\title{
التدريس الفعّال لمهارة المحادثة للمستوى المتقدم
}

\author{
Othman bin Musa Alsa'di* \\ Sultan Qaboos College of Arabic Language for Non-Native Speakers, Oman
}

\section{Effective Teaching of Conversation Skill to Advanced Level}

\section{E-Mail Address}

othman77s@hotmail.com

${ }^{*}$ Corresponding Author

\section{Keywords}

Effective teaching; conversation skill; advanced level

\begin{abstract}
This research aims to present my experience in teaching the advanced level of conversational skills in the Sultan Qaboos College for teaching Arabic to other speakers using the effective teaching method to deal with questions such as: What will I do when I teach the advanced level of conversation and how will I study it? Will the topics be exciting for motivation in different classroom situations? Will the conversation be effective in the classroom and beyond? The study concluded with the importance of providing the participants in the teaching of Arabic to foreigners with practical experience, mechanisms, and interactive methods, and to fill some of the shortage in this field of knowledge and by following the descriptive-analytical approach. It also included the topics studied in this experiment. The most important conclusion: the importance of correct assessment of students before starting to teach the best way to success Effective teaching, patience is also necessary for successful linguistic production, in addition to motivation as well as the synergy of methods and principles of effective teaching all leads to the integration of the student gradually in the Leah classroom and with his colleagues and with the environment is not class later.
\end{abstract}

\section{المقدمة}

لاشكَّ أنَّ للمحادثة أهميةً كبرى عند دراسة اللغات، فهي المفتاح الذي يلج به الدارس إلى عوالم الناطقين باللغة، مما يسهل عليه التمكن من اكتسابها بمختلف مهاراتها. وبما أنّ جلّ الدارسين القادمين إلينا في كلية السلطان قابوس لتعليم اللغة العربية للناطقين بغيرها هدفهم الأساسي تطوير مهارة المحادثة ، فكان حريٌ بنا نحن مدرسي الكلية البحث عن وسائل ثتير دافعية الدارس، وتحفزه لكسر كل الحواجز لممارسة اللغة في بيئة متنوعة بالمثيرات، وهو ما أطلقت عليه بالتدريس الفعَّال لمهارة المحادثة. إضافة إلى ما خرجت به توصيات بعض المؤتمرات ذات العلاقة باللغة العربية وتعليمها، فنوَّهت إلى ضرورة تطوير أساليب التدريس بصورة عامة والمحادثة بصورة خاصة. 
ورغم كون المحادثة إحدى المهارات الأربع التي يدرسها متعلم اللغة العربية للناطقين بغيرها، غير

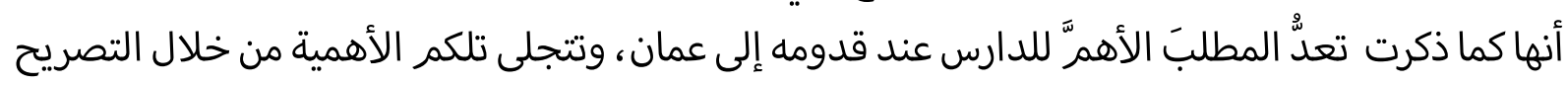

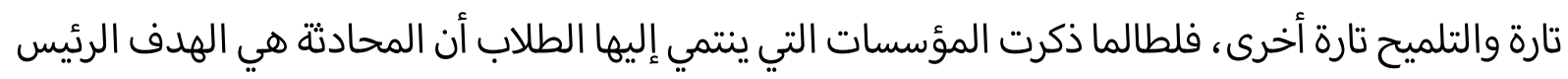
من إرسال الطلبة إلى عمان، وكذلك الطلبة أنفسهم يصرحون بذلك عند وصولهم إلى عمان خصوصا في في المقابلة التمهيدية لتقويم قدرات الطالب، وقياس مدى ملائمته للمستوى، فالغالبية العظمى من الطلبة تصرح أن المحادثة ورغبة التقدم فيها ثمثل رأس الهرم ضمن أهداف قدوم الطالب إلى عمان، مع عدم مدري ملائه إهمال المهارات الأخرى بطبيعة الحال وهي الكتابة والقراءة والاستماع إضافة إلى المحادثة.

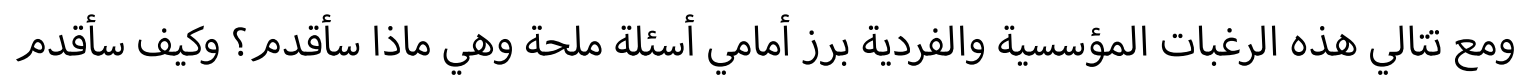
المحادثة؟ مما دفعني للاطلاع على حزمة من المصادر في هذا المجال مثل: كتاب الكتاب لمحمود البطل وكتاب أهلا وسهلا لمهدي العش والعربية بين يديك للفوزان وآخرين، وعربية الناس لمنذر يونس، وغني وغيرها من المناهج المعدة لتعليم العربية للناطقين بغيرها. ومما لاحظته أنَّ هذه الكتب في بنيتها وضعت لتدريس المهارات الأربع دون التركيز على مهارة المحادثة، وعند مواصلة البحث وقع بين يدي كتابان: الأول موسوعة المحادثة الإنجليزية لخالد الخطيب وسامي صقر وهو كتاب مفيد رغم أن حقله ليس تدريس اللغة العربية بل تدريس اللغة الإنجليزية ، وسبب الفائدة احتواؤه على التعبيرات المستخدمة في التحية والتعبير عن النفس والاستئذان والاقتراحات وغرفة الصف ومتجر الملابس والمطعم والتاكسي والفندق والمطار والتوجيهات والنصيحة والتحذيرات والأمثال الشائعة ... الخ ورغم تقديمه للمحادثة الإنجليزية مشفوعة بترجمة عربية يمكن توظيفها في تدريس العربية إلا أنه في أصل وضعه ليس معدا لتعليم اللغة العربية وإن احتوى مادة منها، إضافة إلى أنه مفيد في المستوى المبتدئ، أما المستويان المتوسط والمتقدم فلا يمكن الاعتماد عليه لتدريسهما، عدا غياب الثقافة العربية عن المحادثات (al-Khațīb \& Ṣaqr, 2015). أما الكتاب الثاني فهو لديفيد سيمور وماريا بوبوفا وهو "•• نشاط صفي في المحادثة والوظائف والقواعد والمفردات". ورغم أنه غير مختص في تدريس مهارة المحادثة إلا أنه يعد من المراجع المهمة في تدريسها وذلك لتعدد المواضيع المطروحة وطرق تقديمها مثل الإقامة والحيوانات والجريمة والعقاب والثقافة والتعليم والموضة والغذاء والمستقبل والجغرافيا والصحة والأبطال والبطلات في حياة الإنسان والتاريخ والإجازة والراحة والمال والمحاورة والصحف والسياسة والعلاقات والعلوم والتكنلوجيا والرياضة والقصص والتلفزيون والوقت والمواصلات والعمل (Seymour \& Popova, 2003). ولا شكَّ أنَّ هذهِ المواضيع متنوعة ومثيرة وشاملة لمختلف جوانب الحياة وطريقة تناولها متدرجةحسب المستوى أولا، وثانيا حسب طريقة التقديم ، فهناك الحوار بين الأستاذ والطلبة وكذلك بين

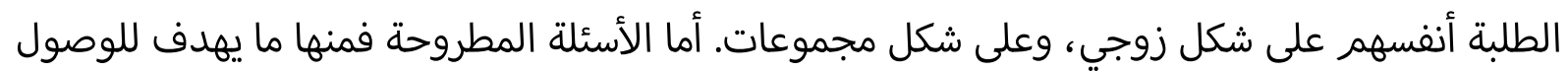

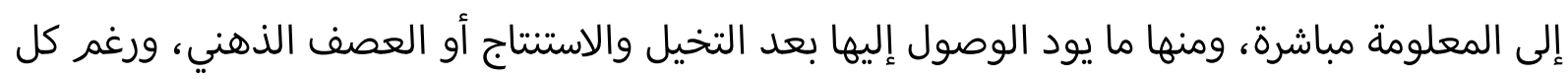
هذه الإيجابيات يبقى أن هذا الكتاب يستهدف دارس اللغة الإنجليزية وليس العربية، ولذا فإن جزءا كبيرا 
من المعلومات المقدمة تتضمن الثقافة الإنجليزية ومعلومات عن الدول الناطقة باللغة الإنجليزية غالبا، وكذلك المكونات البشرية والمكانية والفنية والثقافية والغذائية وتغيب عنه المفردات الثقافية العربية مما يسهم في تسرب شيء من الملل إلى المتعلم. إضافة إلى كتاب ثالث اطلعت عليه وأفدت منه وهو دراسة الدكتوراة المعنونة بفاعلية برنامج مقترح لتنمية مهارتي الحوار في اللغة العربية لدى غير الناطقين بها ،دراسة ميدانية في المعهد الفرنسي للشرق الأدنى وهي بحث لنيل درجة الدكتوراة في المناهج وطرق التدريس أعدته د مهى أبو حمرة عا•r-10.r بجامعة دمشق بكلية التربية قسم المناهج وطرق التدريس. فاحتوى الملحق رقم (•ا) من الدراسة برنامجا مقترحا لتنمية مهارتي الحوار في اللغة العربية لدى غير الناطقين بها،وأهم المواضيع بين دفتيه الطعام عند العرب والأجناس الأدبية العربية وبعض المواقف الاستماعية والبصرية والألعاب اللغوية. ورغم كمية الحوار المنتشرة في الدرس الواحد وتنوعها وتدرجها بين ثنايا الدرس بدءا من التمهيد ومن ثم العرض

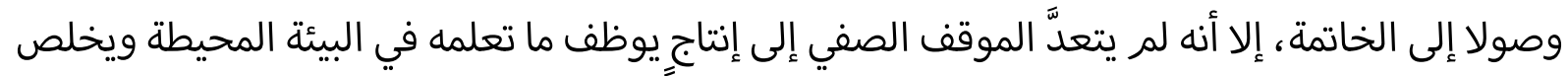
إلى إنتاج فعال يتفاعل معها (Mahā, 2014). بناء على ما تم ذكره ورغبة في الحصول على مادة تحوي الفائدة والإثارة فلقد صممت دروسا عند تدريسي للمستوى المتقدم من الدفعة الحادية والثلاثين يحوي دروسا تركز على مادة المحادثة بعد أن

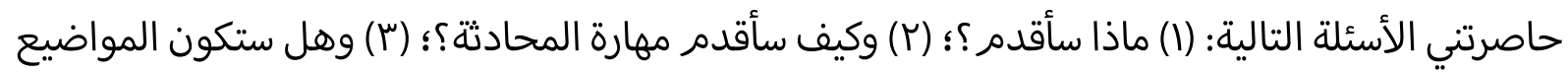
والطرق مثيرة للدافعية في مختلف المواقف الصفية؟؛ (ع) وهل من الممكن أن تكون المحادثة فعالة ؟ وهل من الممكن أن تدفع الدارس للتفاعل مع المجتمع الخارجي؟ وما أقصده بالفعالية هنا أنْ يتفاعلَ الطالبُ مع زملائه ومع الإنتاج اللفظي لهم في الغرفة الصفية من جانب، ومن جانب آخر أن تكون لدى

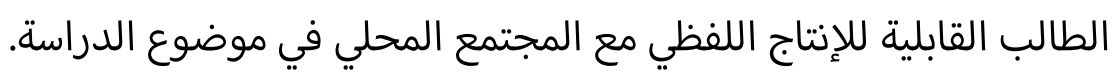
تبرز أهمية هذه الدراسة في النقاط الآتية: (ا) تزويد المشتغلين بتجربة عملية في تدريس مهارة المحادثة؛ (Y) تقديم مجموعة من الطرق والآليات التفاعلية في تدريس مهارة المحادثة في الغرفة

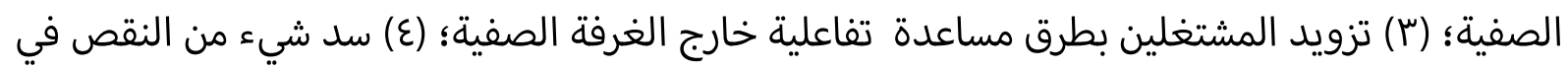
الحقل التربوي في مجال طرق تدريس المحادثة بطريقة فعالة تحول تجربة الدراسة إلى تجربة عمادها الممارسة.

\section{منهج البحث}

أما المنهج الذي سأتبعه في هذه الدراسة فهو المنهج الوصفي التحليلي، لأوضح به أهم المواضيع وطريقة تناولها وسبب التناول، وآلية التقويم. 


\section{نتائج البحث والمناقشة}

أ. الت التدريس الفعال والطرق والآليات

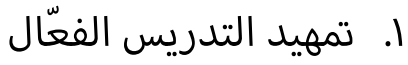

التدريس الفعال طريقة قوام العملية التعليمية فيها يرتكز على الطالب كونه هو الهدف الأول والأخير من العملية التدريسية ، ولذا إذا ما تم الانطلاق منه لفهم الدرس وشرحه وتقويمه فإن ضمان نجان نجاح العملية التعليمية سيكون في أعلى النسب دائما. وكما ذكرت بدوي فإن التعلم لم يعد عملية سلبية موجهة خارجيا بل هو عملية فعالة ونشطة وبناءة وموجهة ذاتيا (Badawī et al., 2016). ولذا فإنها تسعى لأن يكون الطالب إنب التيك هو المحور الرئيس للعملية التعليمية كما يورد حنافي جواد في تعريفه للتدريس الفعال فيقول : "هو ذلك النمط من التدريس الذي يجعل من المتعلم محورا رئيسا، فلا يكون الطالب فيه متلقيا للمعلومات فقط المكا،

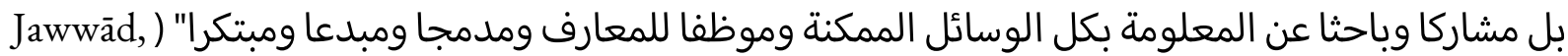

وعند الإمعان في هذا التعريف وأهدافه البعيدة فلا غرابة إن خلصنا إلى أنه يفتح المجال واسعا

للنشاط الذاتي والمشاركة الإيجابية للمتعلم بتوظيف الأنشطة المختلفة كالملاحظة والمقارنة ووضع الفرضيات والاستتتاج وقراءة البيانات، وبهذه السبل مجتمهة يروم تنمية القدرة الذاتية الواعية للارتقاء

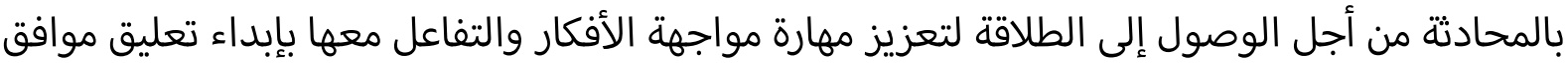
أو مخالف أو أي تعليق يراه. ومن التعريفات التي تقدم للتدريس الفعال ما تركز على الاستراتيجيات المنفذة في الغرفة الصفية فلقد أوردت الحارثي () تعريفا لنايفة قطامي يقول: "هو التدريس الذي يهتم فيه المعلم بتنمية استراتيجيات التدريس وتطويرها وتنويعها في معالجته للمحتوى العلمي، حيث لا يقتصر دور الاستراتيجيات على تلقين وتتبيت المعلومات بل يتعداها إلى توجيه نشاط الطلاب توجيها ثابتا ودائما،

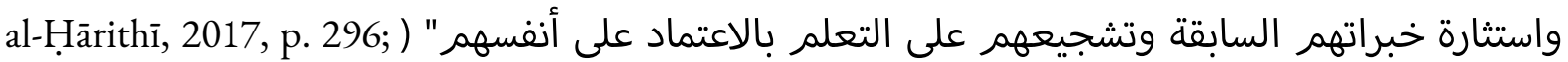

(Quțāmī, 2004, p. 358

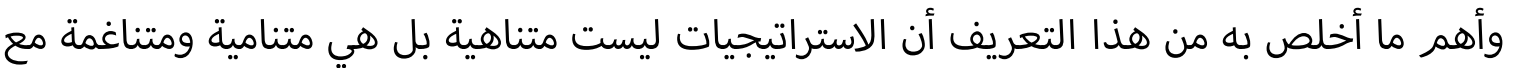
الهدف الأسمى وهو وصول الطالب للمعلومة وتفاعله معها، وأضيف إليه أن ليس كل اليست استراتيجية تنجح

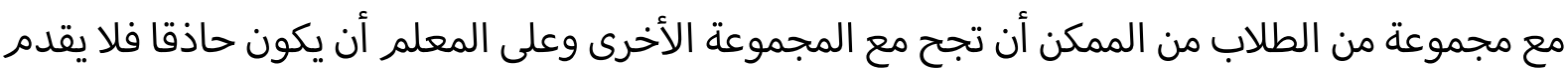
الأساليب نفسها مع كل الطلاب.

ويورد حنافي جواد سبع مبادئ تسهم في نجاح التدريس الفعال وهي تشجيع التفاعل بين المتعلم والمتعلمين وتشجيع التعاون بينهما، وتقديم التغذية السريعة والدعم الفوري،واعتبار التقويم بجميع

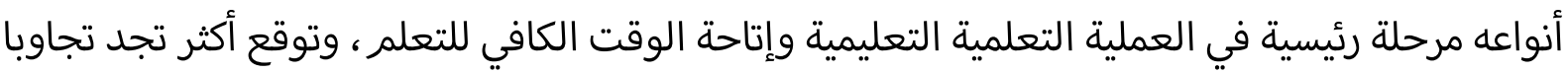


أكثر ، والإيمان أن للمتعلمين أساليب تعلم مختلفة ويجب تفهم ذكاءهم (Jawwād, 2011). وتضيف إليها الحارثي التعزيز بأساليب مختلفة والتكرار والقدوة (al-Hārithī, 2017, p. 312). إن هذه المبادئ في غاية الأهمية للحصول على أفضل نتيجة للتدريس الفعال فملازمة التشجيع من المعلم وإيمانه العميق بنجاح الطالب تسهم في دفع الطالب إلى المحاولة تلو المحاولة من أجل تحقيق

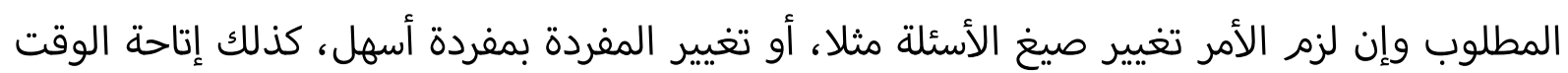
الكافي لها دور كبير في اكتساب الطالب للثقة خصوصا في البدايات، وتوقع أكثر تجد أكثر من المبادئ

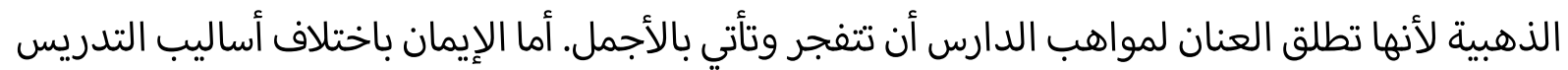

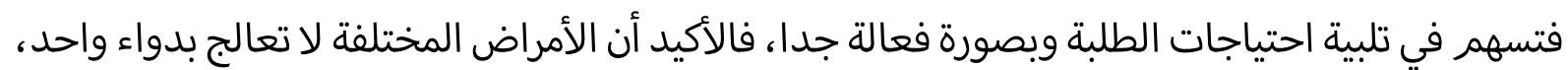
وكذلك المعرفة لا تقدم بطريقة واحدة وإن كان الطلبة في مستوى واحد.

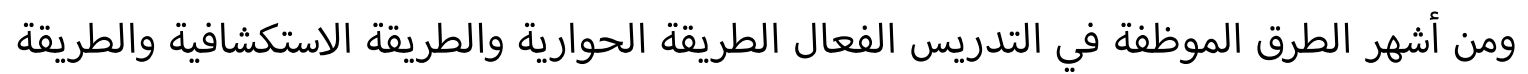

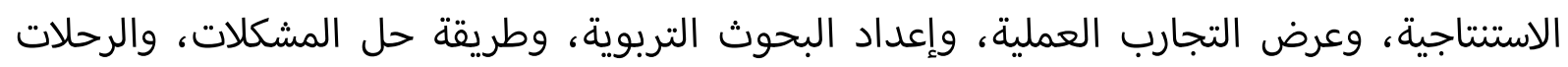
العلمية العملية والزيارات وطريقة المشروع والتدريس بالمجموعات والعصف الذهني. وللأهمية التي

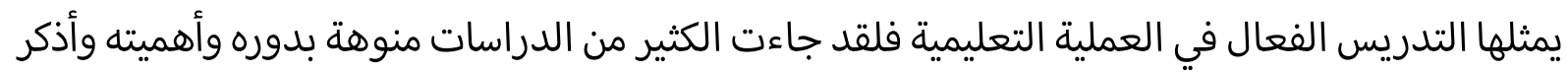

دراسة صلاح خليفة خدادة اللامي وعبد الزهرة لفتة عداي البدران، وعنوانها "ما مدى تحقيق التدريس الفعال: الممارسات التدريسية للأستاذ الجامعي". وهدفت الدراسة إلى الإجابة على الأسئلة التالية:مدى تحقق مهارات التدريس الفعال في التدريس الجامعي،وهل توجد فروق ذات دلالة وفقا لمتغير الجنس والمرحلة؟ وهل توجد فروق وفقا لمتغير الإنسانيات- العمليات؟ وخلصت : إلى فلى أن

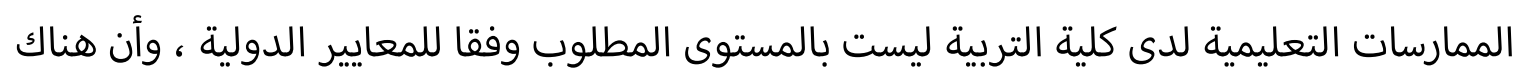
ضعفا واضحا في معايير التدريس الجامعي. ولا شك أن هذه الدراسات رغم النتائج السلبية التي

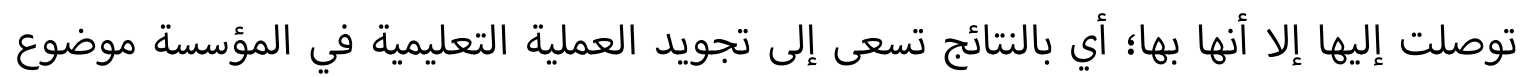
الدراسة (al-Lāmī, \& al-Badrān, 2013). ب) دراسة هناء محمد أحمد أخميس، وعنوانها "درجة ممارسة معلمي الصف الأول لمسارات التدريس الفعال للقراءة". وهدفت فيها التعرف إلى درجة ممارسة معلمي الصف الأول للتدريس الفعال للقراءة وتقصي الفروق في درجة ممارسة تلك المسارات بغرض لفت الانتباه إلى تحسين مستوى معلمي الصف الأول في التدريس الفعال في القراءة، وخلصت إلى أن ممارسة المعلمين لمسارات التدريس الفعال للقراءة بشكل عام مرتفعة، وعزت الباحثة ذلك للوزارة ودورها في التدريب ،ومما خلصت إليه أيضا عدم وجود فروق حسب متغير الصف والجنس وعزت ذلك إلى تحمل المسؤولية من المعلمين ذكورا وأناثا من أجل الارتقاء بمستوى الطلاب وكذلك التغيرات التي عرفتها المناهج،

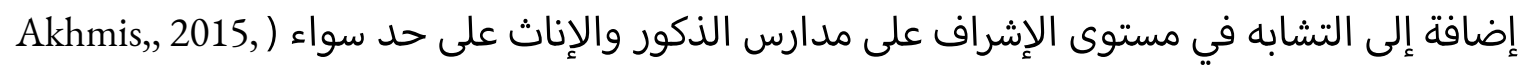


ومما استخلصه من هذه الدراسة أهمية التدريس الفعال بوصفه استراتيجية ناجحة في مجال التعليم Tuwij, ) وتجلت هذه الأهمية في تطوير المناهج والمتابعة والإشراف من قبل وزارة التربية والتعليم 2017). وإزاء كل ما تقدم وبناء على وضوح الهدف الرئيس لي من مهارة المحادثة فإني ارتضيت العمل بطريقة التدريس الفعال رغبة مني في جعل الطالب اللاعب الأساسي في الموقف الصفي بدءا من التعرف ماء مهاء على المفردات وإنتاج الجمل بها ومن ثم القراءة ومناقشة الأسئلة حول النص المساعد (وهو عبارة عن نشاط حواري عماده طالبان أحدهما يقرأ مقالا والآخر لديه كلمات مفتاحية وبينما ينشغل الأول بالقراءة

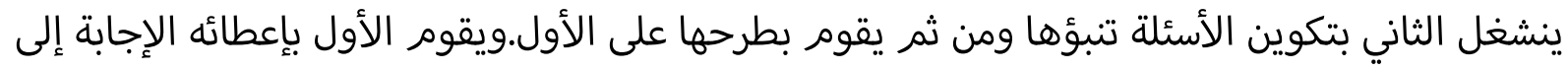
أن يحصل على الموضوع أكمله، ثم يعيد انتاجه شفويا للأول ويقارنان مدى تطابق المعلومات). وصولا إلى الإنتاج والمتمثل إما في مشروعِ أو نشاط واحد مع مع واحِ احد (وسيع الحوار) وكذلك العرض الشفوي،

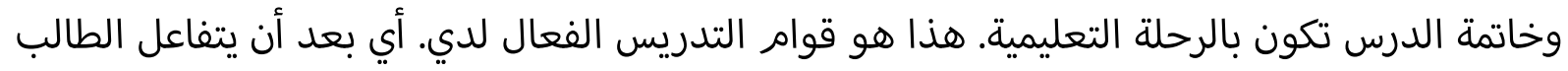
مع الموضوع لا يكتفي به وبالأسئلة السابرة بعده ، بل يتعرض للنص المساعد والمشروع وواحد مع واحد بـد بلد والتقديم الشفوي والرحلة التعليمية.

r. الطريقة والأساليب الطريقة التي اعتمدتها في التدريس هي الطريقة التواصلية لتناسبها مع الأهداف المرجوة من مهارة المحادثة ولإتاحتها الفرصة الكبيرة للطالب في ممارسة اللغة أما الأساليب التي استخدمتها في هذه الطريقة:

$$
\text { أ) أسلوب الحديث الحر }
$$

وهو عبارة عن مساحة زمنية أعطيها للطالب للحديث في أي موضوع يشاء بشرط أن يلتزم بمحددين اثنين

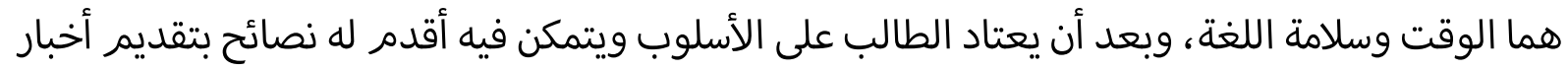
مختلفة في الرياضة والسياسة والطب والصحة، ووما أذكره أن طالبة قالت لي في المقابلة التعريفية أنها لا تستطيع أن تقيم أي حوار في المجال الطبي وبعد اتباع هذا الأسلوب تغير الأمر لديها.

$$
\text { ب) بأبران النصي }
$$
وأقصد بالبرلمان النصي أن يكون لدى كل مجموعة من الطلاب مقالا حول موضوع الدراسة مثل درس

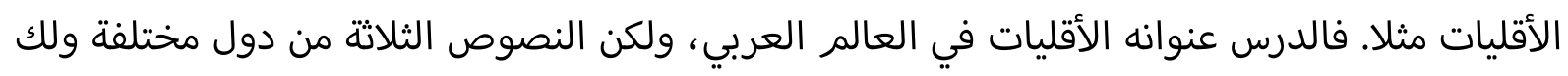
مجموعة لديها أقلية وبعد ذلك كل مجموعة تحاول أن تكتشف الأقلية وفي أي دولة ونسبتها المئوية بالنسبة إلى عدد السكان الإجمالي، والتحديات التي تواجه الأقلية... الخ. 
ج) واحد مع واحد

وهو الخطوة الثالثة من كل درس أطبقه مع الطلبة وفكرته أن الطالب الدارس يتقابل مع زميله، وأحد الطالبين لديه النص والآخر لديه كلمات مفتاحية من النص، وبينما ينشغل الطالب الذي لديه النص بقراءته فإن الطالب الآخر يكون أسئلة من أجل الوصول إلى الموضوع، ومن ثم يعيد سرده على زميله مكتملا أولا،

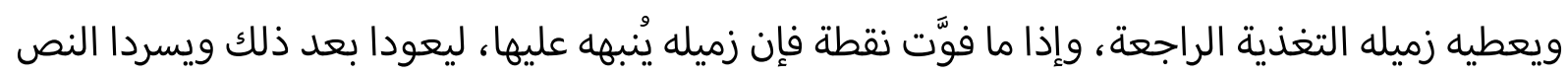
أمام بقية الصف.

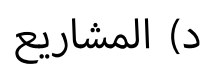

ينصب الجهد بعد استيعاب فكرة الدرس على تقسيم الطلبة إلى مجموعات وكل مجموعة تصممٌ مشروعا لإيصال فكرتها ومن المهم جدا أن تختار طريقة عرض نهائية له، وطريقة تسويق، مثال على ذلك في في درس اله البيئة نقسم الطلاب إلى مجموعات وكل مجموعة تقدم مشروعها في حفظ البيئة ومن ثم نحول الفكرة إلى مشروع قابل للتطبيق على أرض الواقع ونسوق شعاره أو أهم معالمه على شكل مطبوعات مجات على القميص أو الكوب أو الميداليات ونوفر بيئة حقيقية لعرضه تتمثل في زيارة كلية أو مدرسة أو إقامة معرض يتحدث الطلبة فيه عن مشروعهم.

0) المناظرات وهنا نقسم القاعة الصفية إلى قسمين وقسم يكون مع الفكرة وقسم آخر يكون ضد الفكرة، وبعد أن يتعرف الطلبة على مفردات الموضوع ، وأفكاره الرئيسة يتم طرح الموضوع للتناظر، مثال على ذلك الك الك

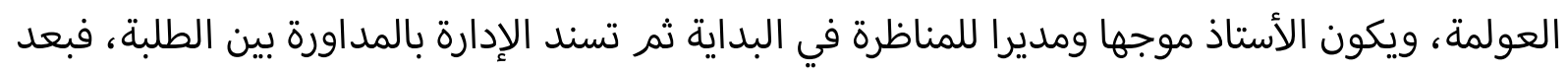
تناول جوانب العولمة السياسية والاقتصادية والاجتماعية والثقافية والرياضية والفنية يتم إعطاء كل جانب لأحد الطلاب للحديث معه وكل كاجانب من الفريق الآخر للحديث ضده، ومن ثم إعطاء كل طالب فرصة

للتعقيب مرة واحدة فقط.

و) العروض الشفهية وبعد أن يكون الطالب درس النص الأصلي ودرس النص المساعد، وتحاور مع زميله في واحد مع واحد، وأتى بخبر قصير حر، وكون مشروعا، يأتي الوقت للحديث لمدة خمس دقائق عن موضوع له صلة بالموضوع الرئيس المدروس، فمثلا إذا كان عنوان الدرس الأقليات في العالم العربي، يختار الطالب أقلية 
ز) الرحلة التعليمية يوم الخميس وفي هذه الرحلة يتجلى تفاعل الطالب مع البيئة المحيطة بعد أن تفاعل مع زملائه في البيئة الصفية من

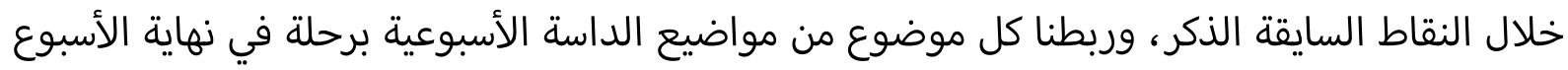

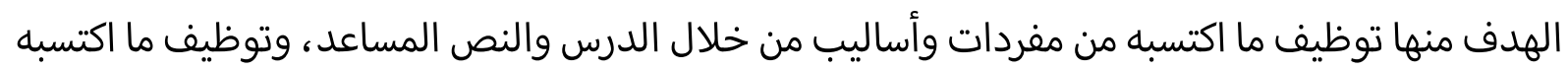

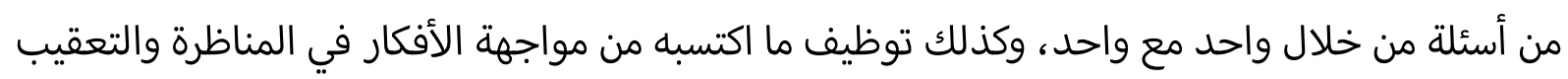

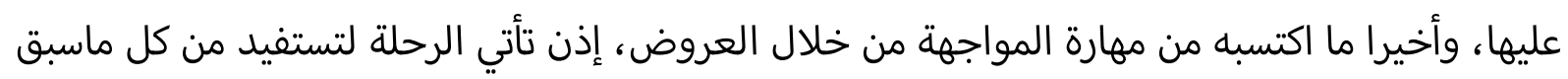
وتمكن الطالب من التفاعل بنجاح مع البيئة الخارجية خارج الغرفة الصنا منار الصفية.

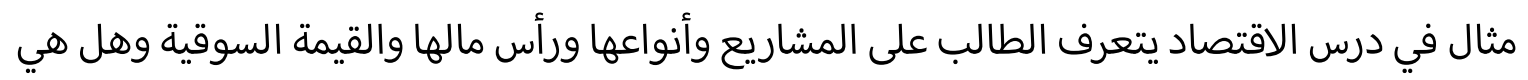

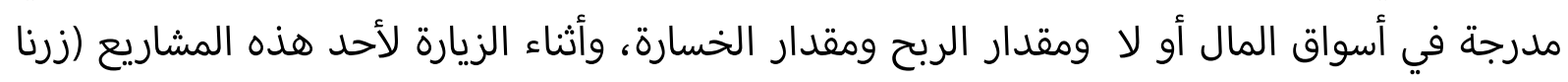

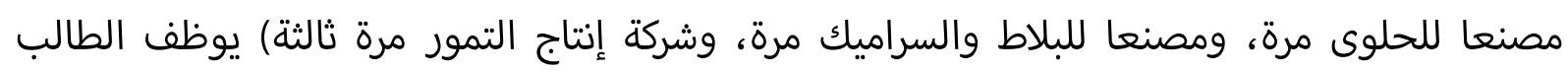
المفردات ومن ثم ينتج نصا يعرف فيه بالشركة .

ح) الواتساب

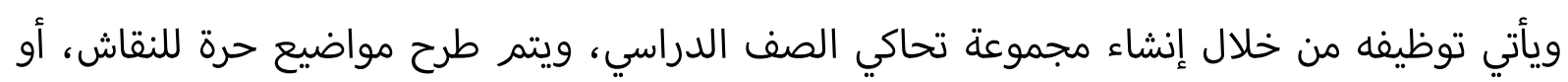

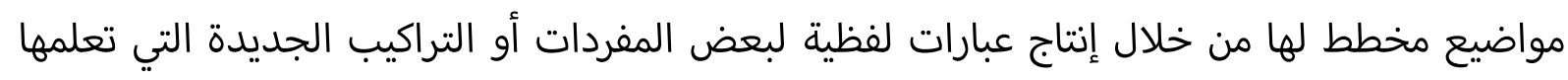

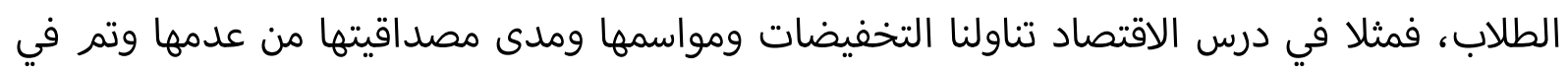

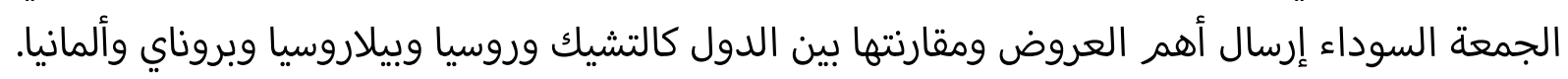
إضافة إلى إرسال بعض مقاطع الفيديو وطلب أجمل تعليق عليها.

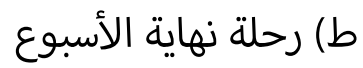

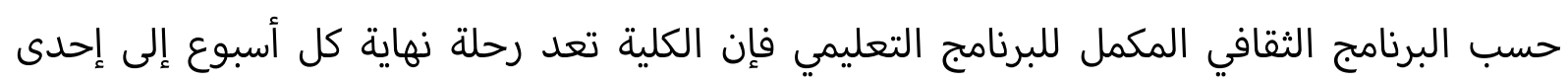

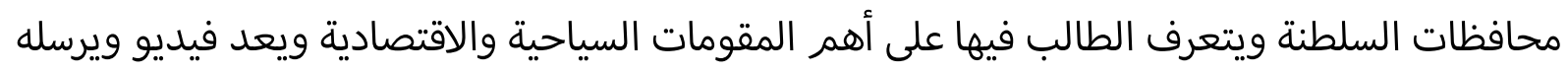

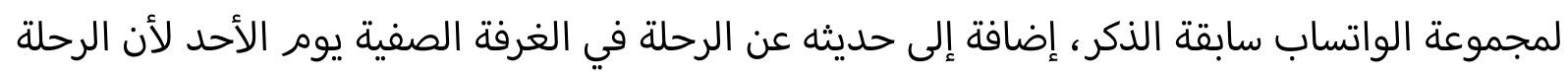

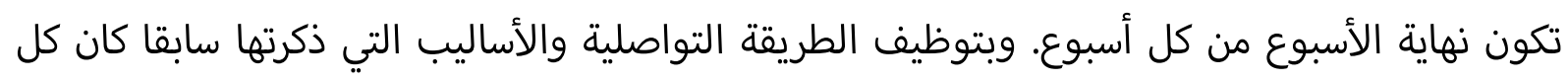



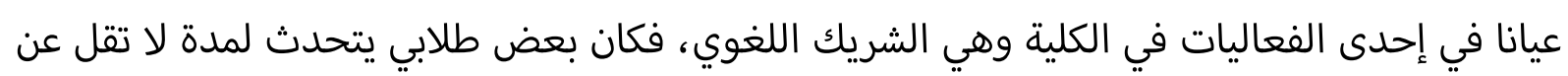
عشر دقائق عن الاقتصاد موظفا أهم مفردات الدرس التي تعلمها الطات الطالب.

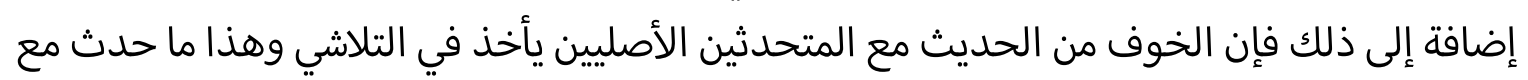

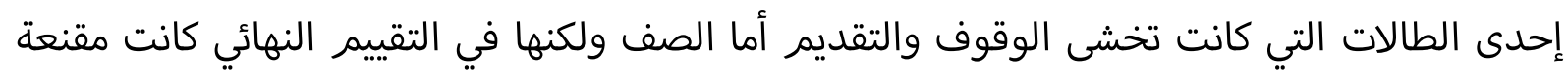

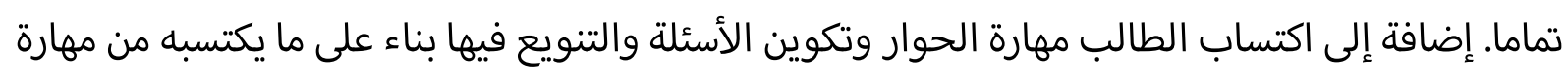


واحد مع واحد، إضافة إلى الجرأة في العرض وتقديم المشاريع بناء على ما اكتسبه الطالب من مهارة في المشاريع. وأذكر أنني في درس حوار الحضارات كان من مفردات الدرس تعريف الطلاب على أحد المبادرين في هذا الجانب وقدم مشروعا بعنوان سفير لغتي وثقافتي وبعد أن تعرف الطلاب على فكرة المشروع وأهدافه وإنجازاته والتحديات التي واجهته ، انقسموا إلى مجموعات وكل مجموعة قدمت مشروعا واختارت الطريقة المناسبة لتسويقه. وفي الأسابيع المقبلة دعيت إلى فعالية ثقافية ووجدت الطالب يقدم مشروعه في الصف في تلك الفعالية للتعريف ببلده، وكم شعرت بالفخر أن ما ينتج في الغرفة الصفية يحمل صفة الديمومة وليس حدثا صفيا عابرا.

ج. المواضيع ونموذج تطبيقي والتقييم ا. المواضيع التي درستها في هذا المستوى

\begin{tabular}{|c|c|c|c|}
\hline ملاحظات & الأساليب & الموضوع & الأسبوع \\
\hline • - زيارة مدينة نزوى & 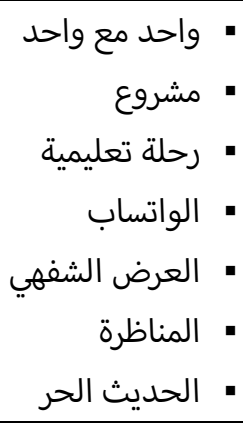 & - & الأسبوع الأول \\
\hline • • ل ز زيارة مصنع البلاط & 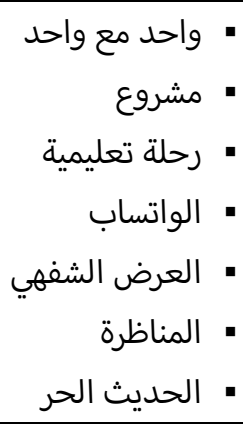 & - & الأسبوع الثاني \\
\hline • • - زيارة دائرة & 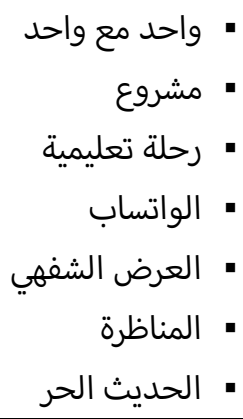 & الصحة والبيئة & الأسبوع الثالث \\
\hline • زيارة المدارس & • • وشروع مع واحد & الأقليات & الأسبوع الرابع \\
\hline
\end{tabular}




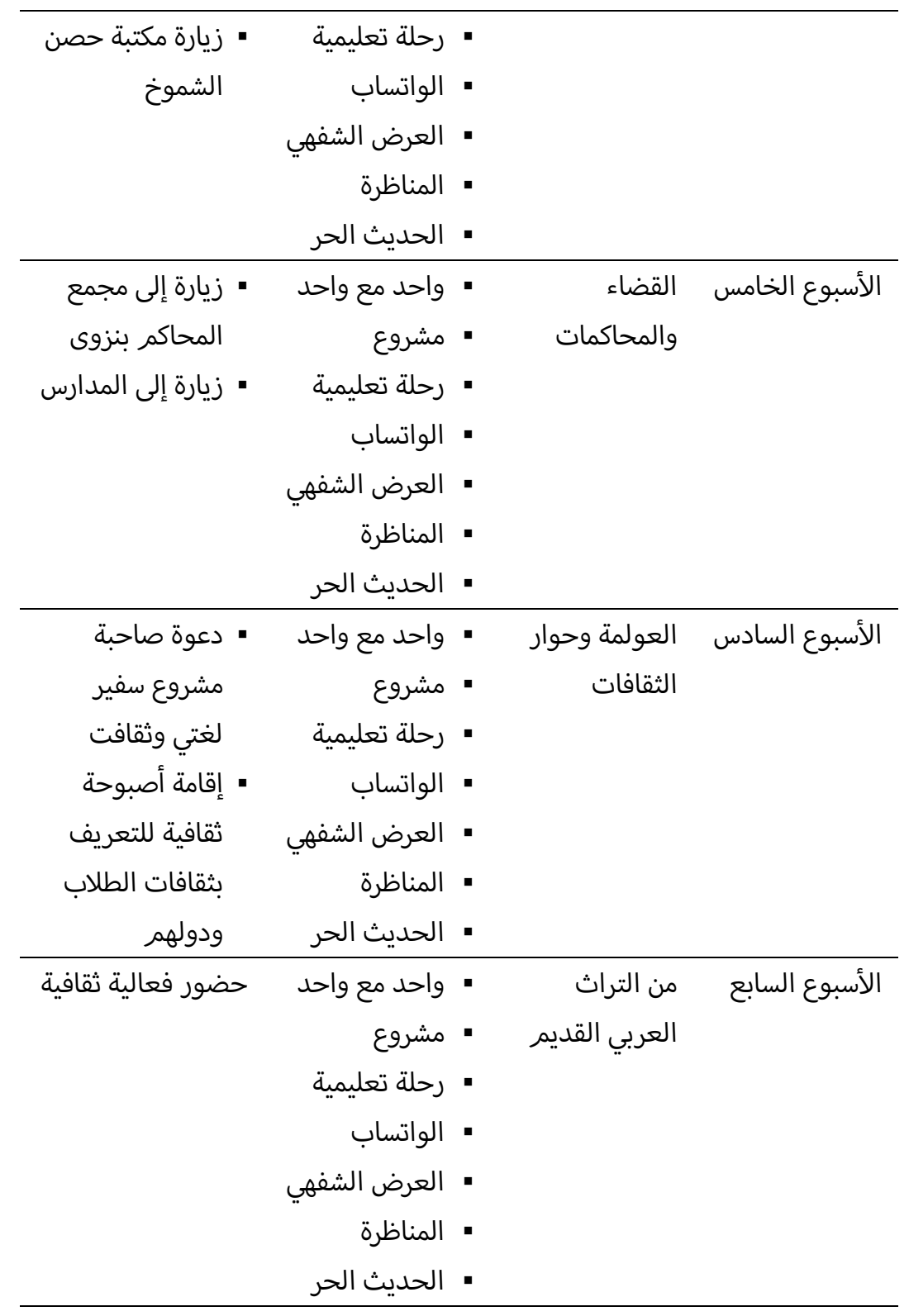

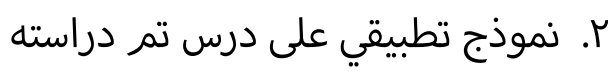

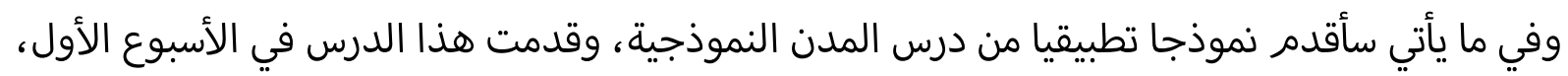

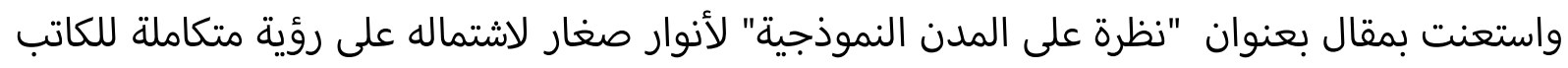

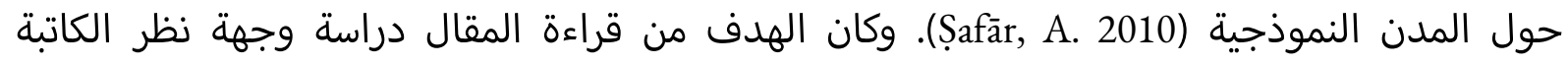
ومناقشتها، وتلمس موقف الطلاب منها وسبب ذلك الموقف:

أ) أمفردات

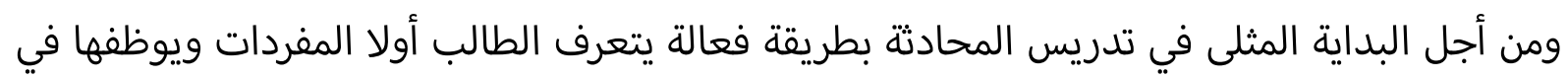
جمل، وبعد أن أتأكد من تمكنه منها فإنه يكون فيها سؤالا ويختار طالبا من الصف ويسأله ذلك السوالك السؤال 
الذي كونه فيما أسميه لعبة الأسئلة والمفردات التي كانت في هذا الدرس هي:هذه أبرز المواضيع التي تم دراستها في الغرفة الصفية والتفاعل معها من الطلاب، ومن ثم تم التفاعل مع البيئة المحلية من أجل توظيف ما تم اكتسابه وأحسب أن الفائدة كانت كبيرة جدا حسب الاستبانات التقييمية في التغذية الراجعة لمختلف الأساليب الموظفة في الغرفة الصفية.

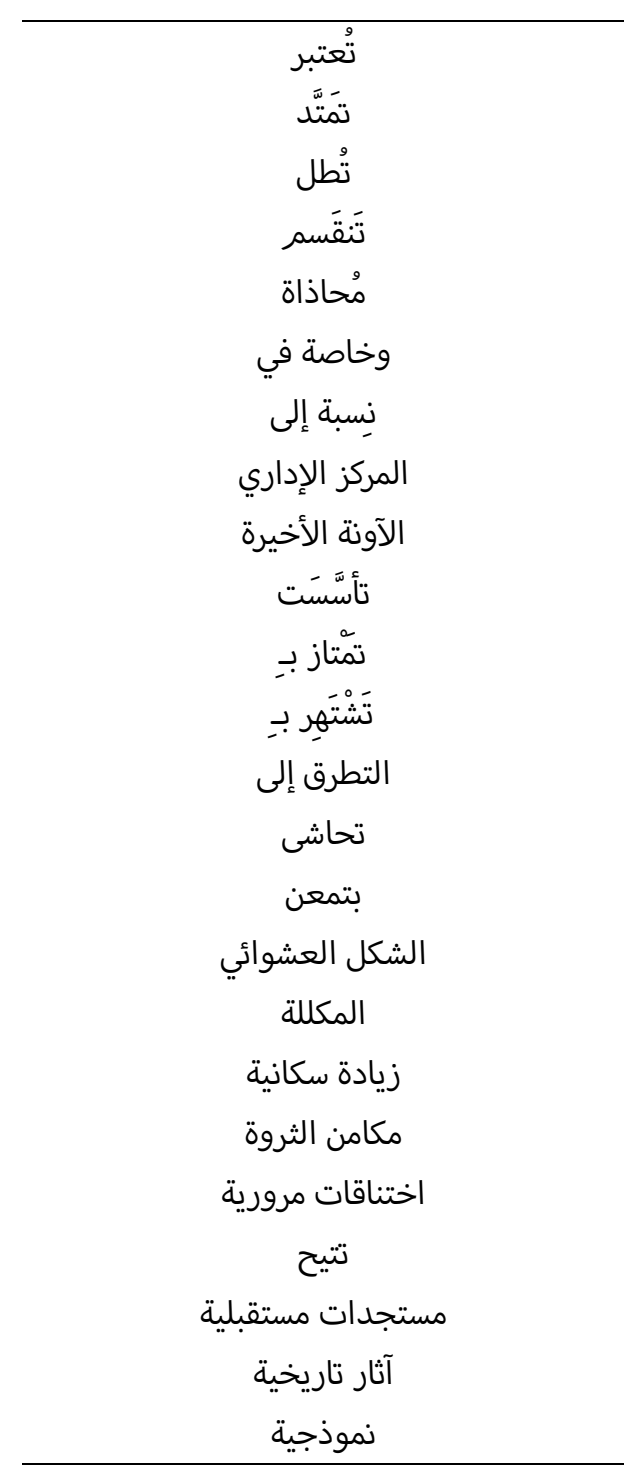

وإذا ظهرت صعوبة في بعض المفردات فمن الممكن أن ألجأ إلى فكرة تكوين قصة انطلاقا من إحدى الكلمات ثم يكمل الطالب الآتي القصة معتمدا على الكلمة التالية وهكذا. وتلي هذه الخطوة تمرينات تقيس تمكن الطلبة من المفردات مثل: • اختر الكمة المناسبة وأكمل بها الفراغ. (مُحاذاة، تتطرق إلى، تحاشى، بتمعنٍ، بشكل عشوائي، المكللة، مكامن، تتيح)

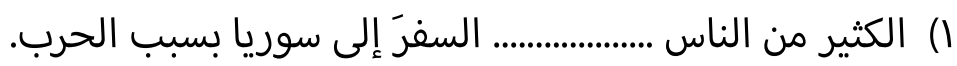


إلى الإعصار فلورنسا الذي يضرب السواحل الأمريكية حاليا.

r) الإنسان الناجح يمشي بخطةٍ ولا يمشي



تجعل الإنسان متعلما جيدا. 0

بالاجتهاد تحقق الأهداف. 7) الدراسة

للطلاب الفرصة للتحدث باللغة العربية. V

القوة في نفسك ولا تستسلم.

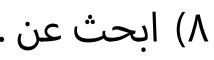

\author{
• صل بخط بين الكلمات التالية:

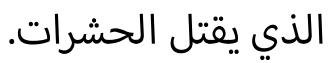 \\ اللاجئون \\ إتلاف \\ الناس التي تركت بلادها بسبب الحروب غالبا

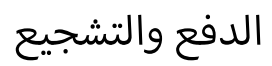

التهيئة يتم من خلالها تهيئة الطالب من أجل أفضل تفاعل مع المقال وأهم الأسئلة الممتناولة فيها:

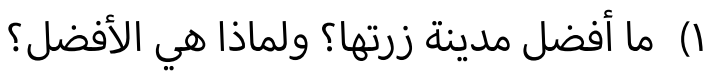

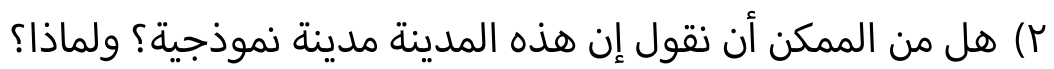


ع) الآن سنقرأ مقالا بعنوان نظرة على المدن النموذجية لأنوار صغار، هل تتوقعون المدينة النموذجية التي سيقدمها؟ (وأكتب التوقعات لزيادة الحماس)، وبعد ذلك أوجه لهم سؤالا بعد الانتهاء من قراء المقال فكروا في هذا السؤال: 0) هل تتفقون مع الكاتبة أن هذه المدينة هي المدينة النموذجية؟ ج) الأسئلة النقاشية وبعد ذلك ندخل إلى عوالم المقال ويتم تقسيمه إلى فقرات، ويتم مناقشة كل فقرة وأسئلتها، مع الحرص على إشراك الطلبة جميعا في النقاش. مثال على الأسئلة النقاشية: () ما الموضوع الذي تود الدارسة التطرق إليه في هذا المقال؟

r) اذكر ثلاثة أخطاء وقع فيها مخططو المدن الذين سبقونا؟ 
"r) لماذا ترى الكاتبة أننا نحتاج إلى نوع جديد من التخطيط المديني؟

ع) ما هدف الدارسة من هذه الدراسة؟

0) ماذا يعني نصف جهان؟

7) كيف تطور الإسكان في مدينة أصفهان حسب الدارسة؟

ما أهم أثر تاريخي موجود في أصفهان؟ V

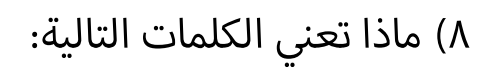

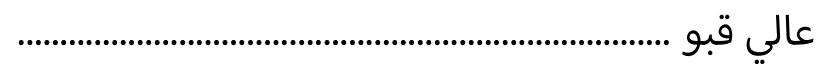

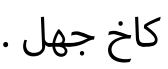

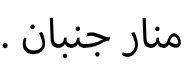

بازار أصفهان . مان.

9) هل تتفق مع الدارسة أن مدينة أصفهان من المدن النموذجية ؟ ولماذا؟

د) النص المساعد

ويتم اختيار نص بأفكار متعددة أو ثلاثة نصوص وينقسم الطلاب إلى ثلاثة أقسام على الأقل وكل مجموعة



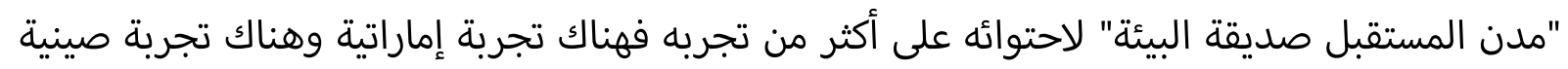

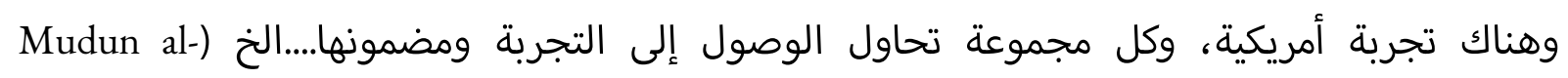

(mustaqbal, 2012

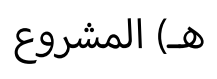

وهنا ينقسم الطلاب إلى مجموعات وكل مجموعة تضع تصورها للمدينة النموذجية المستقبلية وفق محددات رئيسة أهمها: ( أسم المدينة r أهم مرافقها

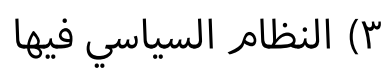
ع) نظام المواصلات 
وفي الختام يكون هناك تقييم للمشاريع ويتم تكريم الجميع بهدايا رمزية وتكريم الفائزين بتحويل مشروعهم إلى منتجات قابلة للتسويق وعرض الفكرة مجددا. مثل طباعته على القمصان أو الأكواب أو الميداليات. وكما ذكرت سابقا فإن أحد الطلاب في مشروع درس حوار الحضارات وبعد دعند دعوة صاحبة مشروع لغتي وثقافتي نفذ مشروعا بعنوان روسيا قلب أوربا وبعد نجاح عرضه في الغرفة الصفية، شاهدته يعرضه في خارج الغرفة الصفية في إحدى الأمسيات معرفا ببلده ومستفيدا مما اكتسبه في الغرفة الصفية. كما لا يمكنني أن أنسى تجربة القناة اليوتيوبية بطاطا بيلاروسية وهي تجرية حية على تفاعل الطالب مع إلى البيئة بعد أن اكتسب المهارات اللازمة.

و) واحد مع واحد. وتم تطبيقه على خمس مدن، لأن الفكرة هنا تقسيم الطلبة بشكل زوجي، وكل طالبين يتناقشان عن مدينة من المدن والأول لديه المقال والثاني لديه الكلمات المفتاحية، والمطلوب حمن لمن لديه الكمليه الكمات المفتاحية: () تكوين الأسئلة الصحيحة.

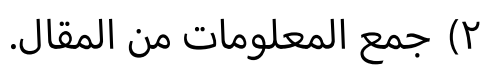
ץ) إعادة كتابة المقال باختصار. وسأقدم نموذجا على واحد مع واحد في التقييم.

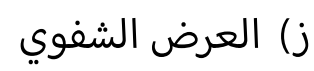

ويختار كل طالب مدينة من المدن التي يحبها ويعرضها أمام زملائه بوصفها المدينة النموذجية ، ذاكرا

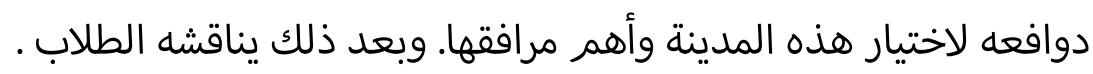

ح) الرحلة التعليمية وبعد أن أتممنا كل مراحل الدرس وتفاعل الطلاب معه بالحديث الحر والنص الأصلي والنص المساعد والبرلمان النصي والمشروع وواحد مع واحد والعرض الشفهي أتى الدور لنقل هذه المهارات والمعلومات والمفردات إلى البيئة المحلية ، واخترنا لتحقيق ذلك زيارة مدينة نزوى والتعرف على أهم ملامحرفها

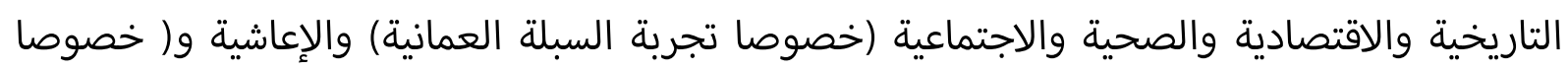
تجربة النزل التراثية) وأذكر أن الطلبة بعد العودة من الرحلة والنقاش مع المختصين كان لديهم إسهاب في الحديث

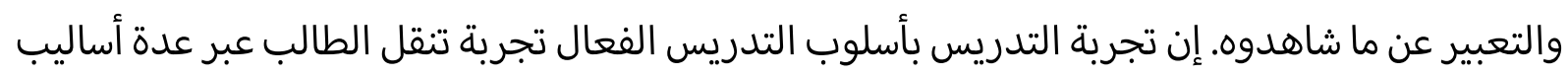
من التعرف إلى التطبيق إلى الممارسة والتفاعل وتجلى أثرها بإيجابية من خلال تدريسي للدفعة التهائ الحادية 
والثلاثين في كلية السلطان قابوس لتعليم اللغة العربية للناطقين بغيرها، ولاحظت الأثر الإيجابي لها في الملاحظة المباشرة في تفاعل الطلاب مع البيئة وفي الاستبانة التقييمية للبرنامج في ختام الدورة.

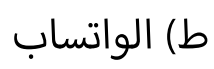
إرسال صور لمدينة نموذجية وفي هذا الدرس من مدينة صلالة العمانية، وطلب أن يعلقوا الطلاب عليها.

س. التقييم التقييم للمحادثة يبرز في جانبيه تقييم تكوني يرافق التمهيد ومناقشة الموضوع والمشروع وواحد مع واحد والعرض الشفهي والرحلة التعليمية. وبالإضافة إليه هناك تقييم ختامي وينقسم بدوره إلى قسمين: (I) اختبار المنتصف من 0 درجات للمحادثة؛ (Y) واختبار نهائي شفوي من •r درجة. ومن نماذج تقييم المحادثة في اختبار المنتصف استخدام (واحد مع واحد) بحيث يكون لدى المدرس المقال ويكون لدى الطالب الكلمات المفتاحية التي ينطلق منها لمعرفة موضوع المقال، مثال: أ) تبدأ محاكمة؟

ب) التهمة / عدد.

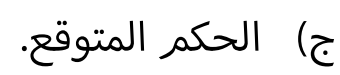
د) المتهم.

) اكتشاف

و) ماذا يقول الخبر:

اسم الطالب/ مادول

وأهم ما يتم مراعاته عند تقييم واحد مع واحد

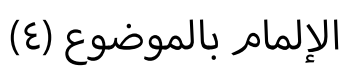

اللغة (r)

بناء الأسئلة (r)

المفردات (r) (باءلاستات 
أما الاختبار الشفوي النهائي فإن الطالب يختار موضوعا من المواضيع التي درسها إما مدينة أ موضوعا في الاقتصاد أو الصحة أو الأقليات أو القضاء والمحاكمة، أو العولمة وحوار الثقافات، أو من التراث العربي القديم ، ويتوسع فيه ويتحدث فيه لمدة عشر دقائق، ويجيب على أسئلة زملائه.

\section{الخاتمة}

وأهم ما خلصت إليه من هذه التجربة: (l) التقييم الصحيح للطلبة في البداية ووضعهم في المستوى المناسب بداية النجاح للتدريس الفعال؛ (r) من الضروري الصبر على الطالب وانتظار الإنتاج اللغوي منه وتحفيزه بأي صورة من صور التحفيز وبعد ذلك ستحصل على غير المتوقع منه؛ (ّ) تعاضد الأساليب التي ذكرتها تجعل الطالب يندمج شيئا فشيئا مع الزملاء في الغرفة الصفية وإن بدا له الأمر صعبا في البداية



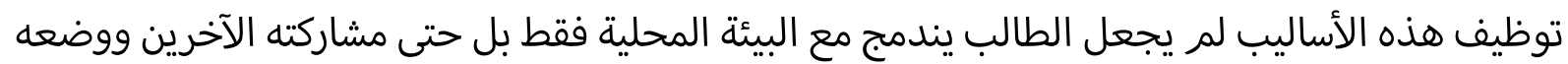
لتصورات للوصول إلى معارض أو مؤسسات وتعريفهم بما قدمه في الغرفة الصفية؛ (0) إن ما لاحظته

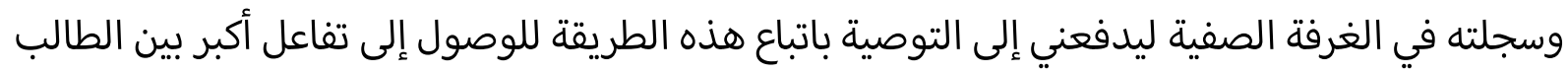
والبيئة المحيطة في مختلف المؤسسات المعنية بتعليم اللغة العربية للناطقين بغيرها.

\section{المراجع}

Akhmis, H. M. A. (2015). Darajah mumārasab mu'allimī al-șaff al-awwal li-masārāt al-tadrīs alfa'äl li-al-qira'ah (Master's thesis). Jāmi'at al-Sharq al-Awsaț. Jordan.

Badawī, M. H., Āl Ziyād, Gh. M. 'A., \& Ibrāhīm, A. S. S. (2016). Istirātījīyāt al-ta'allum al-'amīqah wa-al-sațịiyah wa-atharuhā 'alá ab'ād al-dhakā' al-fa'āl 'inda țullāb wa-țālibāt al-marḥalah althānawìyah bi-madīnat Abhā. al-'Ulūm al-Tarbawīyah, 2(2), 491-556.

al-Ḥārithī, A. S. M. (2017). Mabādi’ istirātījīyāt al-ta'allum al-nashṭ fî ḍaw’ al-naẓarīyah al-tarbawīyah al-Islāmīyah. Majallat Kullìyat al-Tarbìyah bi-Jāmi'at Tanțā, 68(4).

Jawwād, Ḥ. (2011, August 18). al-Tadrīs al-fa'āl. al-Alūkah. Retrieved from https://www.alukah.net/social/0/34045

al-Khațib, Kh., Șaqr, S. (2015). Mawsū'ah al-muḥädathah al-injlizīyah wa-al-qirāa'ah wa-alkitābah. UAE: Dār al-Usrah li-al-Nashr wa-al-Tawzī'.

al-Lāmī, Ṣ. Kh., \& al-Badrān, 'A. Z. (2013). Mā madá taḥqīq al-tadrīs al-fa'āl: al-Mumārasāt altadrīsīyah li-al-ustādh al-jāmi'ī. Majallat al-Khalīj al-'Arabī, 41(3-4), 180-199.

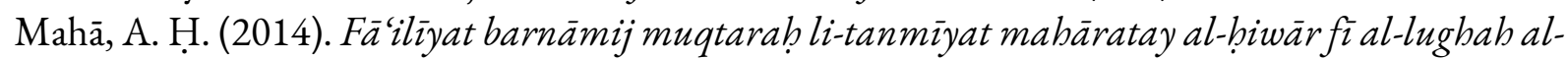
'Arabīyah ladá ghayr al-nātiqina bi-hā. (Ph.D Dissertation). Jāmi'at Dimashq, Syria.

Mudun al-mustaqbal șadīqah li-al-bī'ah. (2012, August 30). al-Jazīrah. Retrieved from مدtps://www.aljazeera.net/news/miscellaneous/2012/7/30/ مد-المستقبل-صديقة-لبيئة

Quṭāmī, N. (2004). Mahārāt al-tadrīs al-fa'āl. Amman: Dār al-Fikr.

Seymour, D., \& Popova, M. (2003). 700 classroom activities. London: Macmillan Education. 
Șafār, A. (2010, April 4). Naẓrah li-al-mudun al-numūdhajīyah. Muntadá. Retrieved from https://eng-art.yoo7.com/t30-topic

Ṭuwīj, S. S. H.. (2017). Athar tadrīs al-lughah al-'Arabīyah bi-istikhdām al-ta'allum al-nashṭ fī tanmīyat mahārāt al-tafkīr al-ibdā'ī. Majallat al-'Ulüm al-Tarbawīyah wa-al-Nafsīyah, 1(1), $38-51$. 